\title{
EFFECTIVE WORK BASED LEARNING ACROSS PROFESSIONS AND THE IMPACT ON THE ROLES OF LIBRARY AND INFORMATION SERVICES: A CASE STUDY OF U.K. PROBATION WORKERS
}

\author{
Dr Graham Walton \\ Service Development Manager \\ Loughborough University Library \\ Loughborough University \\ Leicestershire, UK, LE11 3TU \\ Graham.walton@lboro.ac.uk \\ Jamie Thompson \\ Principal Lecturer, \\ Teaching and Learning, \\ Northumbria University, \\ Ellison Place, Newcastle Upon Tyne, NE1 8ST, UK \\ jamie.thompson@unn.ac.uk \\ Deborah Trayhurn \\ Associate Dean, \\ School of Informatics, Northumbria University, \\ Ellison Place, Newcastle Upon Tyne, NE1 8ST, U.K. \\ deborah.trayhurn@unn.ac.uk
}

\begin{abstract}
Work based learning is occurring in many professions and learners will need access to learning material, information and support if they are to be successful in their learning. Supplying these services within the work context will influence the roles that libraries and librarians fulfil. There is a need to develop a deeper understanding of these developments and the impact on the work of learning resource providers.

A case study approach will explore issues around work place learning using the profession of UK probation workers. We pose key questions:

- $\quad$ Are crucial aspects of knowledge (e.g. tacit knowledge, implicit knowledge, ineffable knowledge) being overlooked?

- Does this approach to knowledge requirement and assessment mean that essential characteristics of professional values, critical judgement, self directed learning and motivation are developed or promoted less as part of learning programmes and support?

Challenges for library and information professions are in creating new relationships with workplaces and workplace learners unconstrained or mediated by programme content. The paper draws on research into the processes of professional development and suggests the need for a new set of relationships to address a changing epistemology of workplace learning.
\end{abstract}

\section{Introduction}

There is no doubt that work based learning will increase in its application in many professions. This trend will also impact on many whose work involves supporting the work 
based learner, including the library and information professional (LIP). The purpose of this paper is to explore how the increased levels of work based learning will influence the future roles of LIPs. There are two aspects to the context of work-based learning:

- $\quad$ policy context that is characterised by increasing governmental pressure to reframe higher education as a supply side to notions of a knowledge economy,

- $\quad$ research context that is founded in an underpinning theory of situated learning.

There will be brief reviews of the United Kingdom context and the notion of situated learning. Issues around the typologies of knowledge in the workplace will be explored. The case study of UK probation officers follows this discussion and enables debate of emergent themes. An analysis of the case study alongside the wide-ranging related experiences of the authors, raises three key areas for LIPs in supporting and delivering work-based learning. These key themes are elaborated and discussed.

\section{Policy context.}

In the UK the National Council for Vocational Qualifications was established in the 1980s. This indicates the steady spread of the codification of knowledge through skill framework developments. A model of skills or competences across employment sectors represents development of knowledge seen as an important economic commodity linked to the efficient management of the workforce. The associated NVQ awards themselves have been supported by the government endorsed Sector Skills Councils. These provide indicators of national skill levels and used as tools for planning up-skilling or workforce development.

At the same time the notion of lifelong learning has gained currency with an underlying theme of continual/lifelong learning for the world of work and the maintenance of employability. Higher Education (HE) has been the last or slowest sector to respond or to be required to respond to this 'new vocationalism'. ${ }^{1}$ In the UK there is currently a radical shift in the funding of HE. The government has set high targets for participation in HE $(50 \%$ of all aged 18 -30 by 2010$)^{2}$ but it has also proposed that University funding shortfall be met by a substantial increase in the fees that universities are allowed to charge (supported by a student loan scheme). Work-based learning has become a significant activity in this attempt to reframe HE. ${ }^{3}$ Institutions are expanding their involvement with businesses and as they respond to the Lambert reports ${ }^{4}$ interest in linking theory and practice will increase.

The debate in UK higher education centres on approaches to the academic accreditation of workplace activity, skills and learning. Most recently focus has been on the added value of university education, to identify the components of graduateness and to assure their delivery. Again these are couched as improved employability expressed in terms of the transferable skills acquired. LIPs have been centrally involved in higher education for many years but there is now a need for re-positioning with the rise of work placed learning.

\section{Research context}

This re-positioning can be enhanced if LIPS have a deeper understanding of the theory of work placed learning and where it differs from traditional education and training. In this section some of the key theories will be identified for LIPs. The overarching theory of workbased learning recognises that it is learning inexorably tied up with (and only happening in relation to) the context within which the learning is taking place. This context is the activity, the relationships and the problems being faced alongside the learning with a "social basis for learning... in direct opposition to a traditional view of a separate and - from the practical context - isolated individual as the centre of the learning process". 5

A number of important contemporary themes emerge from this overarching theory and the associated research and scholarship. 
- Reflection: What is reflection? Introspection? Critical reflection? Typologies of reflection include individual reflection e.g. interactional reflection and notions of organizational reflection. These lead to questions as to whether it is possible to measure reflection or assess reflection?

- $\quad$ Assessment: Another major theme is assessment and clear indications here of different requirements of the worlds of $\mathrm{HE}$ and work. What needs to be assessed?

Professional practice $\mathrm{v}$ academic standards

Competence $v$ academic excellence / level / mark

Able to do v able to write about

Description v critical reflection.

- $\quad$ Learning environments and learning organizations: There is interesting debate about what constitutes a good or ideal learning environment and what the essential characteristics might be for such an environment in the workplace. Furthermore what is the relationship between such environments and notions of a learning organization, or the relationship between learning and productivity?

- $\quad$ Typologies of knowledge: Beyond debates about the relationship between informal and formal learning, discussion seeks to distinguish different types of learning and different types of knowledge. In part this discussion elevates the significance of informal knowledge and learning in the workplace and in part recognises a different order of knowledge, central to effective performance yet hard to measure. This is seen as related to emotional intelligence, the development of personal and professional values and notions of motivation, and called variously tacit knowledge, implicit knowledge or ineffable knowledge. ${ }^{6}$

\section{Exploring the nature of work placed learning using the Probation Service in the UK ${ }^{7}$ as a case study}

In this section the Probation Services in the UK will be used to illustrate further elements of work placed learning. The Diploma in Probation Studies (Dip PS) is the qualification required to become a probation officer in the UK. The Dip PS was built around Occupational Standards (i.e. workplace competences) with a prescribed process and content for the award. An important part of each competence indicated in the Occupational Standards for probation officers, is the underpinning knowledge and understanding. This becomes increasingly significant as the level of the standards rise.

The transparency of a candidate's knowledge and understanding contextualizes their action and is a crucial indicator of competence or developmental need. There are a number of ways in which this knowledge and understanding are evidenced:

- $\quad$ knowledge and understanding may be implicit in action,

- $\quad$ question and answer sessions after observed practice,

- $\quad$ reflective journals, logs and one-off pieces. e.g. analysis of process, selfevaluation or analysis of critical incidents,

- $\quad$ academic assessments designed to be complementary to workplace practice.

The academic curricula have been built around the main strands of the knowledge and understanding requirements and assessment schedules have been designed to provide evidence directly for units. 


\section{Analyzing the knowledge requirements.}

It is clear in terms of Bloom's ${ }^{8}$ taxonomy of cognitive level that the later level in Community Justice is demanding more than simple knowledge and understanding, seeking application of that knowledge and understanding. Further evidence of the higher levels of cognition (analysis, synthesis and evaluation) is also required (see Fig 1 below).

\section{Figure 1 Bloom's levels of learning}

\section{Bloom's levels}

Evaluation

Synthesis

Analysis

Application

Understanding

Knowledge

\section{Learning process}

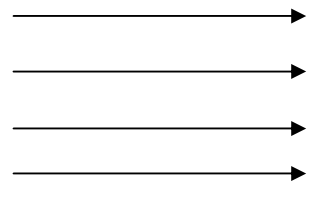

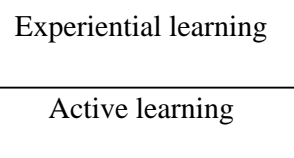

The processes of learning and development are different according to these cognitive levels. Candidate and assessor must move through the necessary instruction phase, creating and using opportunities to apply knowledge to practice through active learning and reach a point at which trainees are reflecting, reviewing and planning autonomously as experiential learners. Higher-level cognitive skills are dependent on a firm foundation.

The Diploma in Probation Studies comprises twelve complementary units with a total of 202 underpinning knowledge and understanding items. The items derive mostly from 11 key themes grouped using 168 of the 171 items (98\%). Some units draw particularly heavily on knowledge and understanding requiring careful structuring of learning to support the achievement. Trainees need to draw on a range of knowledge to demonstrate competence so programmes that deal with themes one at a time always present problems. Trainees commonly express the perceived need to know everything immediately and often feel frustrated at learning that takes place too late.

The generation of these themes from the underpinning knowledge and understanding requirements represents a central or managerial view of a knowledge base for probation. Occupational Standards contribute to the management of learning; providing a standardization process, helping to establish clear boundaries and expectations in relation to particular groups of employees and competences.

The knowledge requirements of the Occupational Standards for Probation are largely non-theoretical as the knowledge described is implicit in observable work behaviour. Further, knowledge is required to achieve a level of competent or good enough practice. The need to know 'why' is largely an unnecessary luxury. However this separation of theory and practice is a flawed paradigm for two reasons. Firstly, theory and practice are much more closely entwined and interchangeable than the paradigm suggests; and secondly, this twin track model overlooks the notion of knowledge in the different but important sense of 'good thinking'.

Taking this model, the process of learning becomes the central consideration. As early as the 1950's Reg Revans ${ }^{9}$ was proposing that prefabricated (or codified) knowledge had limited use in helping people to solve the real practical problems of the workplace. For Revans successful organizations needed to match the pace of change of the external environment with comparable rates of organizational and individual learning. This learning happened most effectively when groups of individuals were given properly structured and supported opportunities to address and solve their own real workplace problems. Revans 
proposed a view of knowledge in which workplace knowledge is grounded in and inseparable from experience. His 'action learning' resonates with androgogical theory where the relevance of knowledge and the safety of the learning environment are central to successful learning taking place.

Another important thinker in relation to learning for work is Donald Schon. Schon ${ }^{10}$ recognised that in complex social spheres the workplace is characterised by the unexpected. He proposed that practice in such circumstances is a form of 'artistry' that can be developed through use of reflective approaches to practice; reflection on practice (learning from practice) and reflection in practice. Reflecting in practice is the key to professional artistry and demands self-discipline, critical awareness and a commitment to a cycle of learning through practice and reflection. Like Revans, Schon was describing a knowledge process grounded in practice where knowledge was not codified but the very currency of continuing personal and professional growth and development.

\section{From codification to learning}

In the Skills Foresight Analysis produced by the Community Justice National Training Organization $^{11}$ some of the sector training and development needs are expressed in terms of knowledge gaps. Codified knowledge often fails to accommodate notions such as confidence and legitimacy. Meanwhile in the same report managers express concern about lack of innovation in practice. Innovation is a crucial part of any complex business and might be expected to thrive in environments where practitioners are encouraged to learn with and from others in tackling difficult problems in the workplace (c.f. Revans) and/or where reflective techniques are made available and encouraged (c.f. Schon).

Probation officers need to draw on knowledge that is often tacit, implicit or indeed, ineffable. Codified knowledge expressed in occupational standards and academic programmes is incomplete and perhaps inadequate knowledge in need of reframing and decodifying to place the practitioner and/or the learner at the heart. Vocational knowledge must be judged in terms of relevance to the practitioner and understood as being mediated through the learner/practitioner. Unlimited by coda and notions of attaining a required standard in a prescribed timescale, probation knowledge should accommodate notions of learner need, embrace the diversity of learner experience and frame itself in terms of a career-long process.

\section{Feelings: last but not least}

Psychology offers us a model to analyse behaviour where action is understood alongside the thoughts and feelings that accompany it. An intrinsic problem in such analysis is in separating out these elements. As a model for understanding vocational development this notion of professional behaviour consisting of thoughts, feelings and actions is a useful tool when evaluating processes designed to prepare individuals for complex jobs. In particular, the inclusion of the emotional as a key element resonates with the lived experiences of doing such jobs. The impact of these feelings on the achievement of successful outcomes is extraordinarily complex. Feelings are invariably present but the extent to which they are transparent varies greatly as does the extent to which the parties are able to recognise, articulate or understand them.

Although there is useful theory to help practitioners understand the place of emotions in behaviour, a vocational notion of emotional intelligence or competence is impossible to describe, inappropriate to prescribe and very difficult to assess. Such a notion of emotional competence is thus absent from the codified knowledge for probation.

Higher Education has much to learn about creating an environment in which students can engage on an emotional level with the content and process of an academic discipline. 
However for trainee probation officers it is the learning environment in the workplace that is critical. There must be encouragement to engage with the emotional content of the work. Trainees need to know that there is not just permission but an expectation to review and reflect upon how they feel. This sort of confidence is unlikely to be experienced unless experienced practitioners and supervisors disclose something of their own emotional experience of the work in appropriate settings.

\section{Emerging roles in work placed learning for LIPs}

So what then of the significance of the probation experience to Library and Information Professionals? Three main roles for the librarian in supporting work based learners have been extrapolated from the probation worker study: developing content, adapting the workplace for effective learning and establishing organisational learning from the work based learners' experiences. This section will explore how these roles are being developed by examination of the United Kingdom's National Health Service (NHS). The NHS is one of the top 5 biggest employers in Europe. At a strategic level it is proposing a coordinated approach to lifelong learning covering personal and professional development ${ }^{12}$ with an education and training budget approaching $£ 2.5$ billion. Work based learning has been recognised as the way to deliver lifelong learning for its workforce. ${ }^{13}$ The UK NHS provides a good context to demonstrate how these three roles have emerged for librarians in supporting work-based learning.

\section{Content development.}

Despite our reservations about the nature of codified knowledge it is clear that HE needs to become increasingly responsive to the particular knowledge and skills requirements of specific employment sectors. LIPs have an important role to play in working across the divide between academic and vocational codifications of knowledge with librarians taking the lead in raising awareness across $\mathrm{HE}$ about the ways in which knowledge is codified and in framing knowledge resources in relation to work-based/vocational as well as traditional subject based HE codifications. Increasingly LIPs need to engage with the tensions between the iteration of knowledge in HE programmes and needs-driven knowledge progression in the workplace, with the complexities of engaging with knowledge for capability / competence as well as knowledge for understanding.

Librarians have long been involved in developing and delivering content for the learner, increasingly this is being done within the electronic context. Providing learning resources electronically has some major advantages for the work-based learner.

1. It gives the learner desktop access at the point of need in work situations (as long as connection to Internet is available)

2. Work patterns which involve changing locations and frequent moving are best met by electronic learning resources

3. When the work force is distributed, central collections of print learning resources will disadvantage some. Providing the work based learner with electronic learning resources provides equity

4. A specific advantage for electronic learning resources access to support workbased learning in the NHS is the power of economies of scale. An extensive and diverse range of learning resources can be purchased economically for NHS employees. In 1998 the Department of Health agreed to begin the National Electronic Library for Health. Its primary mission is to support evidence-based decision-making in healthcare but it also has major role in 
delivering learning resources. The NeLH complements existing libraries as it 'concentrates on fast and easy electronic only access to research evidence, clinical guidelines and critically appraised resources' ${ }^{14}$. It has recently been re-badged as the National Library for Health.

(http://www.library.nhs.uk/).

Two key areas have to be addressed in delivering electronic learning resources to the work-based learners (over and above the quality of the resources): marketing and partnership working. The National Library for Health can provide some important lessons regarding marketing for others involved in supporting work placed learning. They have found that there is a need to "infiltrate daily working lives so that using...resources becomes natural". ${ }^{15}$ Multiple communication routes are needed to effectively convey the existence of electronic learning resources to the work-based learner. Partnership working can also enhance the development of learning resources for the workplace and can begin to address the complexities and shortfalls of codified knowledge bases and to develop innovative processes and content. Effective partnership practice should be developed with all the key stakeholder groups. These include learners, trainers, managers, ICT staff and other learning resources providers. Much can be gained from small-scale projects that can then be developed and rolled out as services.

\section{Adaptation of the workplace.}

It is clear that HE has been slow to recognise the changing learning environment in the workplace. HE has engaged slowly with the connections between traditionally delivered packages of learning and workplace discourse around employability, competence, capability and lifelong learning. In leading and supporting the development of learning environments the LIP will need to be aware of this discourse and embrace the notion that such environments are not just about flexible access to knowledge resources. Importantly they are also about access to and participation in processes through which problems can be solved and individual learning needs addressed.

Librarians have amassed considerable experience in providing appropriate environments to facilitate effective learning. They are positioned well to adapt the workplace so the work-based learner can be successful in their learning. It has been pointed out ${ }^{15}$ that there is a need to "accommodate different approaches to teaching and learning which recognises that students learn from each other and therefore at times need to work in groups". Many libraries now provide a diverse range of environments offering different learning spaces. For example at Oxford Brookes University four zones are made available: group work/ discussion area, traffic area, quiet study area for individuals where silence cannot be guaranteed and silent area. ${ }^{16}$ Work-based learners will develop their own learning style and learning behaviours in the workplace. An argument has been proposed ${ }^{15}$ that customer satisfaction is often dependent on their direct/ indirect interactions as they share a service facility's physical environment. In the workplace, the interaction of employees (not all of whom will be learners) will influence the quality of learning for those who are engaged in workplace learning. Library staff have to appreciate what can be done to manage or influence positively the way employees work together to learn. Librarians are ideally equipped to evaluate the workplace and establish how the different learning experiences needed by the workplace learner are best provided. They can also use their experience in working with different clients to identify how best the work-based learner can be supported by the organisation. 


\section{Learning through learners' experience}

Learners' experiences in the probation example reflect the inadequacy of codified knowledge to meet important aspects of professional learning and development. To succeed at work requires adequacy in terms of knowledge and skills, a clear sense of legitimacy, confidence in a range of support (including emotional support) and the ability to solve problems and innovate. These are important characteristics that need to be delivered in a learning environment.

The third role for librarians in work-place learning which emerges from the probation worker study, is that concerned with establishing organisational learning from the learners' experiences. The concept of the 'learning organisation' emerged in the early 1990's through work by Senge ${ }^{17}$ but finding a concise definition is difficult. Garvin ${ }^{18}$ proposes that a learning organisation is "an organization skilled at creating, acquiring and transferring knowledge and at modifying its behaviour to reflect new knowledge and insights”. Roles for librarians emerge in various facets. Garvin states that a learning organization should demonstrate: problem-solving, experimentation, learning from own experiences/ history, learning from others' experiences/ best practices and transferring knowledge quickly and efficiently throughout the organisation. There is a pressing need to develop a detailed understanding of the workplace learner so various questions can be answered. How does the workplace learner differ from other learners? What support does the work placed learner need? What resources do work-based learners need?

Librarians can take responsibility for such areas as evaluating the learners' experience, benchmarking work place learning in other organisations, trialling services and then facilitating change in the organisation. An example of this role and resulting activities is provided in work exploring how health students learn in the work setting. ${ }^{19,20}$ This study was undertaken by people from a library background but the investigation focussed on areas not previously seen as being within the 'library' context. It provided evidence and concepts that were used to make the workplace learning experience more effective and efficient.

\section{Conclusion}

If work-based learning is not to be a degraded form of learning then the central role of the LIP in providing a range of support must be recognised.

- $\quad$ Physical access to libraries may not be easy for work-based learners. LIP expertise in ongoing distant access to appropriate material in increasingly important.

- However the LIP role goes beyond this 'technical' expertise. The librarian needs to support and promote organizational development in the workplace and develop close working relations with employers and those delivering learning in the workplace.

- $\quad$ The LIP must evaluate, research and reflect on the learning experience in the workplace and develop a good understanding of the experience of learners and employers in order to deliver ever more supportive and effective services.

- $\quad$ Beyond this there are two particularly challenging questions that begin to emerge. First, to what extent can LIPs draw on a culture in which the learning organization and lifelong learning experience are central in supporting their own work-based learning? Finally, how clear are the boundaries of the librarian role when librarians are increasingly concerned with supporting the processes of learning as a crucial part of delivering the resources for learning? 


\section{References}

${ }^{1}$ Symes C. \& McIntyre J. (eds) Working Knowledge: The New Vocationalism and Higher

Education. Buckingham: SRHE/Open University Press, 2000.

${ }^{2}$ Clarke, C. The Future of Higher Education. London DfES, 2003.

${ }^{3}$ Brown, R. The Work Related Learning Report. London: DfES, 2002.

${ }^{4}$ Lambert, R. Lambert Review of Business-University Collaboration: Final Report. London: HMSO, 2003.

${ }^{5}$ Svensson, L., Ellstrom, P. \& Aberg, C. Integrating formal and informal learning at work.

The Journal of Workplace Learning 2004, 16 (8), 471-482.

${ }^{6}$ Coffield, F. (ed.) The Necessity of Informal Learning. Bristol: Policy, 2000.

${ }^{7}$ Whitehead, P. \& Thompson, J. Knowledge and the Probation Service. London: Wiley, 2004.

${ }^{8}$ Bloom, B. S. Taxonomy of Educational Objectives: The Classification of Educational Goals. London: Longman, 1964.

${ }^{9}$ Revans, R. W. The ABC of Action Learning. London: Lemos and Crane, 1998.

${ }^{10}$ Schon, D. Educating the Reflective Practitioner. San Francisco: Jossey-Bass, 1987.

${ }^{11}$ Community Justice National Training Organisation. Skills Foresight Analysis. London: CJNTO, 2003.

${ }^{12}$ Great Britain. Department of Health. Working Together - Learning Together: A Framework for Lifelong learning in the NHS. London: HMSO, 2001.

${ }^{13}$ Anon. Emphasis on study for the NHS, Nursing Standard 2002, 16 (40), 17.

14 Turner, A. The National Electronic Library for Health. In: Walton, G. \& Booth, A. (eds) Exploiting Knowledge in Health Services. London, Facet, 2004.

${ }^{15}$ Rowley, J.E. Customer compatibility management, or re-visiting the silence rule? Library Review 1995, 44 (4), 7-12.

${ }^{16}$ Brewerton, A. Noise annoys? SCONUL Newsletter 2000, 21, 50-53.

${ }^{17}$ Senge, P.M. The Fifth Discipline, New York, Doubleday, 1990.

${ }^{18}$ Garvin, D.A. Building a learning organisation. Harvard Business Review 1993, 71 (4), 78 92.

${ }^{19}$ Walton, G. Translating recommendations into practice and developing further research: case study of survey into health students' learning resources needs. Paper presented at Using Research in Practice day, iSHIMR Conference, Sheffield, 17 ${ }^{\text {th }}$ June 2004.

${ }^{20}$ Walton, G., Smith, A., Gannon-Leary, P. \& Middleton, A. Supporting learning in practice in the enquiry based learning curriculum: a collaborative approach to ensure nursing preregistration students have access to learning resources in the placement setting. Nursing Education in Practice (forthcoming) 2005. 